$\begin{array}{ll} & \text { Etnográfica } \\ \text { etnográfica } & \text { Revista do Centro em Rede de Investigação em }\end{array}$

Antropologia

vol. 20 (3) | 2016

Vol. 20 (3)

\title{
Correspondências de cientistas sociais brasileiros para Jorge Dias: duas margens de uma interlocução transatlântica
}

Letters from Brazilian social scientists to Jorge Dias: two margins of a transatlantic dialogue

\section{Ana Teles da Silva}

\section{(2) OpenEdition}

\section{Journals}

\section{Edição electrónica}

URL: https://journals.openedition.org/etnografica/4685

DOI: 10.4000/etnografica.4685

ISSN: 2182-2891

\section{Editora}

Centro em Rede de Investigação em Antropologia

\section{Edição impressa}

Data de publição: 1 outubro 2016

Paginação: 607-630

ISSN: 0873-6561

\section{Refêrencia eletrónica}

Ana Teles da Silva, «Correspondências de cientistas sociais brasileiros para Jorge Dias: duas margens de uma interlocução transatlântica», Etnográfica [Online], vol. 20 (3) | 2016, posto online no dia 27 novembro 2016, consultado o 10 fevereiro 2022. URL: http://journals.openedition.org/etnografica/ 4685 ; DOI: https://doi.org/10.4000/etnografica.4685

\section{(c) (†) 8}

Etnográfica is licensed under a Creative Commons Attribution-NonCommercial 4.0 International License. 


\section{Correspondências de cientistas sociais brasileiros para Jorge Dias: duas margens de uma interlocução transatlântica}

\section{Ana Teles da Silva}

O presente artigo centra-se nas correspondências entre estudiosos do folclore e cientistas sociais brasileiros com o antropólogo português Jorge Dias. Trata-se de, a partir destas correspondências, levantar questões sobre os estudos de folclore no Brasil e o desenvolvimento da antropologia brasileira, verificando-se alguns paralelos com a antropologia portuguesa. Discutiremos aqui as relações estabelecidas entre estudiosos do folclore e cientistas sociais brasileiros com o antropólogo português Jorge Dias. A análise destas relações revela alguns aspectos sobre: a busca das origens portuguesas da cultura brasileira por parte de intelectuais, sejam brasileiros, sejam portugueses; o lugar da cultura popular na construção de uma imagem de nacionalidade em ambos os lados do atlântico; e as relações entre ciências sociais e estudos de folclore.

PALAVRAS-CHAVE: estudos de folclore, ciências sociais, cultura popular, intelectuais, nation building, redes luso-brasileiras.

Letters from Brazilian social scientists to Jorge Dias: two margins of a transatlantic dialogue - The article focuses in letters written by Brazilian social scientists and intellectuals interested in folklore studies to the Portuguese anthropologist Jorge Dias. This correspondence raises questions about folklore studies and the development of anthropology in Brazil, showing parallels to Portuguese anthropology at the time. The analysis of the relationships established between Jorge Dias and Brazilian scholars is revealing of: how both Portuguese and Brazilian intellectuals looked for the Portuguese origins of Brazilian culture; the role of folk culture in the construction of an idea of nation in both sides of the Atlantic; the relations between social sciences and folklore studies.

KEYWORDS: folklore studies, social sciences, popular culture, intellectuals, nation building, Luso-Brazilian networks.

SILVA, Ana Teles da (silvateles@gmail.com) - Museu Nacional de Belas Artes, Ministério da Cultura, Brasil. 


\section{INTRODUÇÃO}

Fui ao Museu Nacional de Etnologia de Lisboa, em 2014, em busca dos rastros dos estudiosos brasileiros de folclore que tiveram artigos publicados em periódicos portugueses. Queria saber como alguns dos autores da Revista Brasileira de Folclore (1961-1976) haviam publicado nesses periódicos, sobretudo na Revista de Etnografia (1963-1972). Este museu guarda a vasta coleção de objetos materiais reunidos pelo etnólogo português Jorge Dias e sua mulher, Margot Dias, bem como a biblioteca daquele. Seu então diretor, Joaquim Pais de Brito, também antropólogo, conviveu com Jorge Dias, seus colaboradores e Margot Dias, e me recebeu em seu gabinete. Pais de Brito falou de forma entusiasmada sobre Jorge Dias, sua mulher, também antropóloga, e sua equipe.

Margot Dias, já viúva no final da década de 1990, doou o acervo intelectual de Jorge Dias, inclusive seus livros e correspondências, para o Museu Nacional de Etnologia. A exploração da seção da biblioteca dedicada ao Brasil permitiu observar através dos livros, muitos dos quais com dedicatórias, o quanto Jorge Dias aproximou-se de autores brasileiros e brasilianistas. Na pasta de correspondências do Brasil, além das cartas recebidas por ele, há apenas duas que são respostas de Jorge Dias. Desta forma, embora não tenha encontrado material sobre a Revista de Etnografia, pude visualizar através das correspondências de brasileiros com Jorge Dias o intercâmbio próximo estabelecido com intelectuais portugueses e relações, por vezes tensas, entre estudos de folclore e ciências sociais no Brasil. Este artigo, portanto, se sustenta na correspondência de Jorge Dias com autores brasileiros que ainda não haviam sido trabalhadas. ${ }^{1}$

A proximidade entre Jorge Dias e os cientistas sociais brasileiros teve como um dos seus pontos importantes o fato de aquele ter estado no Brasil para ministrar cursos e participar em congressos durante cerca de seis meses em 1950, subsequentemente participando em vários eventos acadêmicos. As relações mais intensas de Dias com o Brasil ocorreram na década de 1950. Ele participou nos Congressos de Folclore, organizados pela Comissão Nacional de Folclore em 1951, 1953 e 1954, e no XXXI Congresso Internacional de Americanistas, realizado em 1954. O contato de Dias com a Universidade do Paraná foi um dos mais efetivos, e nos anos de 1951, 1953 e 1954 Dias ali ministrou palestras. Em 1954, ele ofereceu também um curso sobre Etnografia Portuguesa no âmbito do projeto de criação do Centro de Estudos Portugueses nessa Universidade. Neste mesmo ano ministrou uma palestra na Faculdade de Filosofia, Ciências e Letras da USP (Lupi 1984: 384). Foram então essas sucessivas deslocações de Dias ao Brasil que terão estado na origem dos laços com estudiosos do folclore e cientistas sociais brasileiros. Esses laços, alguns mais

l Agradeço ao então diretor do Museu Nacional de Etnologia, Joaquim Pais de Brito, por haver viabilizado o acesso a este material, que ainda não estava disponibilizado ao público. 
duradouros do que outros, refletem-se na série de correspondências de Jorge Dias com intelectuais brasileiros. O presente artigo discutirá, portanto, três questões principais, que são: a relação diferenciada que Jorge Dias manteve com cada um de seus correspondentes e reflexões que daí podem ser depreendidas sobre as intercepções entre a antropologia e os estudos de folclore no Brasil; a questão da construção de uma continuidade cultural entre Portugal e Brasil e o empreendimento de nation building presente nos dois países; e uma série de trocas de objetos, contatos e homenagens entre Jorge Dias e seus correspondentes. Temos como hipótese que um dos principais elos de ligação entre Jorge Dias e os intelectuais brasileiros era a busca da continuidade cultural entre Portugal e Brasil. Desta forma discutiremos em que medida a relação entre Dias e os intelectuais brasileiros pode ser explicada por uma antropologia do tipo nation building (Stocking Jr. 1982) nos dois lados do Atlântico.

\section{JORGE DIAS E O CAMPO DAS CIÊNCIAS SOCIAIS BRASILEIRO}

Jorge Dias foi um dos pioneiros na criação do campo acadêmico da antropologia em Portugal. Dias nasceu em 1907, no Porto, e estudou etnologia na Alemanha. Nos seus primeiros anos de pesquisa, interessou-se sobretudo pela cultura material do campesinato em Portugal. Em 1947, Dias foi à reunião da Comissão Internacional das Artes e Tradições Populares (CIAP) da UNESCO, representando Mendes Correia. ${ }^{2}$ Aparentemente, seu conhecimento de várias línguas facilitou sua integração nos grupos formados na CIAP e, em 1954, foi eleito seu secretário geral.

Em 1956, Jorge Dias saiu da Universidade de Coimbra e tornou-se docente do Instituto Superior de Estudos Ultramarinos. A partir daí iniciam-se suas primeiras incursões à África e ele se afasta do Brasil. Dias anuncia estes planos, em sua carta para Florestan Fernandes, de 1956:

"Por isso resolvi aceitar um convite para professor do Instituto Superior de Estudos Ultramarinos e dedicar grande parte da minha atenção aos problemas do Ultramar. Isto já me levou este ano à África, por onde andei quatro meses e onde tenciono fazer uma série de campanhas durante uns anos seguidos".

Dias continua recebendo apelos de alguns correspondentes brasileiros para que retorne ao Brasil, seja na forma de convites para a oferta de cursos, seja para a realização de pesquisas. Renato Almeida, embora não ofereça nenhuma posição para Jorge Dias, lamenta que ele siga para a África e não para o Brasil.

2 Mendes Correia (1888-1960), ligado ao Estado Novo, criou e dirigiu, em 1945, no Porto, o Centro de Estudos de Etnologia Peninsular e convidou Jorge Dias para organizar a seção de Etnografia deste Centro (Matos 2011). 
Em carta de 1956 diz: "Soube, pela Mariza, que esteve aí no Congresso de Braga, da sua ida à África, a percorrer o mundo que o português criou. Prefiro que venha percorrer o lado de cá..."

Henriqueta Rosa, professora da Escola Nacional de Música, busca nas diferenças de temperamento explicar a ausência de Dias dos Congressos de Folclore subsequentes ao de 1954 a que ele compareceu. Em carta de 1960, diz:

"Compreendo não ser possível estar presente em todos os congressos, e reconheço que os brasileiros, por seu temperamento fogoso e às vezes rude não são de molde a saber cativar a simpatia dos seus colegas estrangeiros... Não sei se com ou sem acerto, tive a vaga impressão, no Congresso Internacional de Folclore realizado em São Paulo que alguma coisa o chocara e que, provavelmente, se absteria de participar de futuros congressos realizados no Brasil. Ter-me-ei enganado?"

Apesar do afastamento de Dias em relação ao Brasil, as correspondências com intelectuais brasileiros, que se iniciaram em 1949, continuaram até o ano de 1972, um ano antes de seu falecimento. A década de 1950 foi a mais prolífica em correspondências. Dias correspondeu-se com intelectuais dos principais núcleos em atividade na área das ciências sociais no Brasil dos anos de 1950 e 1960.

\section{CORRESPONDENTES DAS UNIVERSIDADES DE SÃO PAULO}

Um destes núcleos foi o dos professores da Escola Livre de Sociologia e Política (ELSP) e da Faculdade de Filosofia, Ciências e Letras da Universidade de São Paulo (FFCL-USP), duas faculdades criadas em 1933 e 1934, respectivamente.

Entre os professores da ELSP correspondentes de Dias estavam Herbert Baldus e Emílio Willems, este também professor da FFCL-USP. Ambos estes correspondentes eram alemães com formação universitária no país de origem, em Etnologia no caso do Baldus e Filosofia no caso de Willems. Migraram para o Brasil no início da década de 1930 por discordarem da situação política na Alemanha, com a ascensão do partido nacional-socialista. Baldus dedicou-se sobretudo ao campo da etnologia e Willems ao estudo dos imigrantes alemães no Brasil em seu processo de aculturação e a estudos de comunidade. Enquanto Willems deixou o Brasil em 1949 para lecionar no Luso-Brazilian Center da Universidade de Vanderbuilt, nos Estados Unidos, Baldus permaneceu no Brasil, tendo ocupado também a posição de diretor do Museu Paulista entre 1960 e 1965, período em que continuou a se corresponder com Dias. Emílio Willems escreveu 11 cartas para Dias entre 1949 e 1970. Herbert Baldus enviou 12 cartas entre 1953 e 1968. 
Entre os professores da FFCL-USP estavam, além de Emílio Willems, Florestan Fernandes, Gioconda Mussolini e Egon Schaden os últimos três tendo sido orientandos de Herbert Baldus. As correspondências com Florestan Fernandes incluem sete cartas do período de 1956 a 1965. Florestan Fernandes foi professor e pesquisador da FFCL-USP de 1945 a 1969, ano em que foi aposentado compulsoriamente pela ditadura militar no Brasil. ${ }^{3}$ Este intelectual, de origem humilde, é considerado um pioneiro na criação do campo da sociologia no Brasil, e buscou criar uma sociologia científica, afastando-se do ensaísmo até então prevalecente (Arruda 1998: 180). Gioconda Mussolini foi aluna e depois colega de Florestan Fernandes, de 1935 a 1969, quando faleceu, tendo empreendido pesquisas sobre pescadores e estudos de comunidade (Ciacchi 2015). Escreveu uma carta para Dias em 1957. Egon Schaden, oriundo de uma cidade catarinense fundada por imigrantes alemães, foi responsável pela criação da Revista de Antropologia na Universidade de São Paulo e realizou extensas pesquisas com grupos indígenas. Escreveu quatro cartas para Dias no período entre 1955 e 1972.

As duas instituições, FFCL-USP e ELSP foram criadas em São Paulo com os objetivos de modernização do ensino e criação de conhecimento que pudesse ser aplicável ao país. Houve a contratação de professores estrangeiros que pudessem contribuir para este propósito de modernização, tendo a ELSP como mote a criação de elites administrativas para atuar no Estado e a USP a formação de professores para escolas e nas ciências básicas. Essas faculdades fizeram parte de esforços pioneiros de criação de uma tradição científica nas ciências sociais brasileiras, onde até então havia sobretudo esforços ensaísticos, ligados principalmente ao campo da literatura (Peixoto e Simões 2003: 384). A sociologia norte-americana constituiu o modelo da ELSP e a FFCL-USP foi inspirada no modelo universitário francês. É importante perceber que, neste período, a

3 Apesar de as cartas abrangerem parte do período da ditadura civil-militar no Brasil (1964-1985) e da ditadura salazarista (1926-1974) em Portugal, poucas são as referências que fazem a estes regimes políticos. Emílio Willems, talvez por já estar residindo no Estados Unidos, foi o que expressou de forma mais explícita o seu descontentamento com os efeitos do regime militar sobre a vida universitária em carta de 1970, ao comentar o falecimento da colega Gioconda Mussolini: "Não sabia da morte dela, pois quase todos os meus amigos e antigos colegas na Faculdade de Filosofia de São Paulo ou faleceram ou foram aposentados compulsoriamente por um governo ultra-reacionário. Permaneceram as mediocridades". Já Thales de Azevedo, em carta de 1969, ano de endurecimento da ditadura civil-militar no Brasil, comenta quase indiretamente a situação política do Brasil, comparando-a com a de Portugal, que ele enxerga estar num quadro de melhora: "Vocês aí estão em uma esperada aurora política e nós..." René Ribeiro, em carta de 1952, é o único a mencionar o regime ditatorial vivido por Portugal, ao justificar a razão para a UNESCO não financiar um projeto de pesquisa que pretendia desenvolver conjuntamente com Jorge Dias e Gilberto Freyre, relativo a Portugal, Brasil e Angola: "Durante a estada de Metraux aqui falei sobre uma possível colaboração da UNESCO, recebendo uma negativa formal visto o programa de liberdades essenciais do homem defendido por aquela organização chocar-se com o atual regime político de Portugal”. 
profissionalização na área das ciências sociais ainda era incipiente: o doutorado em Sociologia e Antropologia existe apenas na FFCL-USP e é criado em 1947, a ELSP e a Universidade do Brasil, no Rio de Janeiro, ofereciam apenas cursos de mestrado em Ciências Sociais. A criação em maior escala de cursos de pós-graduação acontece apenas com a reforma universitária de 1968 (Corrêa 1988). Florestan Fernandes reconhece semelhanças entre o quadro de profissionalização das ciências sociais no Brasil e em Portugal. Quando parabeniza Jorge Dias pelo ingresso como professor do Instituto Superior de Estudos Ultramarinos, em carta de 1956, comenta: "principalmente porque representa mais um degrau em sua brilhante carreira, em um país parecido com o Brasil a esse respeito: onde não existem posições para os especialistas nas Ciências Sociais". Mesmo assim, Florestan Fernandes, em outra carta de 1956, considera o meio intelectual brasileiro das ciências sociais mais incipiente que o português, no sentido de ser mais personalista. Ele compara portugueses e brasileiros com franceses, ingleses e norte-americanos:

"No Brasil esse processo produz consequências graves, porque os meda-

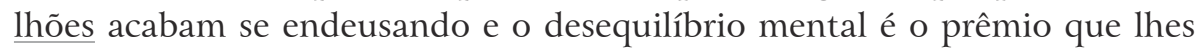
resta, ao fim do drama, dessa avaliação absoluta. O exemplo de Gilberto Freyre é terrível e melancólico. Em Portugal, onde a vida intelectual é, sob diversos aspectos, mais densa e intensa, a fiscalização dos pares e a competição contínua sazonam o ambiente e protegem seus frutos. De modo que o reconhecimento do valor pessoal e da importância das próprias obras são como um prêmio puro, que alegra o sujeito e lhe renova as forças, para novos empreendimentos. Com isso, as chatices da vida e os aborrecimentos pelas limitações do meio ganham corretivos criadores".

As cartas a Dias expressam, portanto, a preocupação de Florestan Fernandes com a maior profissionalização das ciências sociais brasileiras e uma produção mais científica e menos ensaística. Esta preocupação levou Fernandes a buscar uma separação entre os campos das ciências sociais e dos estudos de folclore. Para Fernandes, os estudos de folclore seriam mais ligados ao campo da estética do que ao folclore. Os estudiosos do folclore, por sua vez, que fazem parte de outro grupo de correspondentes de Dias, buscaram no Brasil legitimar o campo dos estudos de folclore enquanto uma disciplina científica, almejando que esta tivesse espaço no meio universitário.

\section{OS ESTUDOS DE FOLCLORE NO BRASIL}

O Movimento Folclórico Brasileiro, conforme indicou Vilhena (1997), tem como marco a constituição da Comissão Nacional de Folclore, em 1948, a partir de uma iniciativa das Nações Unidas para promover a paz entre os povos 
depois da II Guerra Mundial. Com apoio da UNESCO, este movimento articulou uma rede nacional de estudiosos organizados através de um centro, configurado por aquela comissão, que se ligava nos diferentes estados brasileiros às Comissões Estaduais de Folclore. Intelectuais e estudiosos, interessados na cultura popular, de forma mais ou menos diletante, foram chamados a participar nesta rede. Deste modo, esforços anteriores, muitas vezes individuais e sem apoio oficial, foram canalizados para a Comissão Nacional de Folclore (CNF), e nos anos subsequentes para as Comissões Estaduais. Como relatam Cavalcanti e Vilhena (2012), em 1958, o Movimento Folclórico conseguiu uma importante vitória ao obter a sua institucionalização como órgão autônomo do Ministério de Educação e Cultura. Este órgão, chamado de Campanha de Defesa do Folclore Brasileiro (CDFB), foi criado pelo presidente da República, Juscelino Kubitschek, e tinha como objetivo promover pesquisas, divulgar e preservar o folclore brasileiro. Se, por um lado, o movimento obteve vitórias importantes, por outro, em especial a partir dos anos 60, passou a haver uma progressiva perda de espaço dos estudos de folclore no ambiente das disciplinas sociais que se institucionalizavam nas universidades. O desejo de um estatuto de disciplina científica autônoma era almejado pelos intelectuais ligados à CDFB e, com a institucionalização universitária das ciências sociais, em especial com a Reforma Universitária de 1968, que criou os cursos de pós-graduação (Corrêa 1988), este objetivo fracassou, acarretando a visão dos estudos de folclore como uma área de estudos diletantes e amadorísticos.

Apesar de não conseguir o almejado espaço na Universidade, o Movimento Folclórico continuou bastante ativo em outras esferas, como congressos, festivais, publicações, pesquisas, registros e intensa correspondência entre os folcloristas dos vários estados brasileiros.

Renato Almeida, importante articulador do movimento folclórico no Brasil, fundador da Comissão Nacional do Folclore e um dos presidentes da Campanha de Defesa do Folclore Brasileiro, escreveu 16 cartas para Dias entre 1954 e 1965.

Fausto Teixeira, da Comissão Mineira de Folclore, e Dante Laytano, historiador e membro da Comissão Gaúcha de Folclore, escreveram uma carta cada um, em 1954 e 1952, respectivamente. Rossini Tavares de Lima, presidente da Comissão Paulista de Folclore, escreveu quatro cartas para Dias entre 1954 e 1971. Hildegardes Vianna escreveu três cartas nos anos de 1971 e 1972, após ter passado uma temporada no Centro de Estudos de Antropologia Cultural, em Lisboa, com bolsa da Fundação Calouste Gulbenkian. Mariza Lira, presidente da Sociedade de Etnologia, ${ }^{4}$ escreveu 11 cartas entre 1952 e 1959. Maria de Lourdes Borges Ribeiro escreveu duas cartas em 1955. Câmara

4 Apesar desta denominação, este círculo dirigido por Mariza Lira tinha por mote principal o interesse pela cultura popular. 
Cascudo, folclorista do Rio Grande do Norte, um dos mais destacados intelectuais deste campo de estudo e que produziu vasta obra, entre livros e artigos sobre o campo da cultura popular, e foi correspondente da Revista de Etnografia, editada no Porto, escreveu sete cartas entre 1952 e 1960.

\section{ENTRE ANTROPOLOGIA E ESTUDOS DE FOLCLORE}

Os correspondentes do campo da antropologia, que estavam em universidades fora de São Paulo, formam outro núcleo. Alguns destes intelectuais, como José Loureiro Fernandes, Thales de Azevedo e sobretudo Manuel Diégues Júnior transitaram entre o campo das ciências sociais e os estudos de folclore. Thales de Azevedo, com quem Dias correspondeu-se durante os anos de 1957 a 1971, escreveu sete cartas para este. Azevedo, médico de formação, era professor de Antropologia da Universidade da Bahia e participou junto com Charles Wagley ${ }^{5}$ do programa de Estudos e Pesquisas Sociais, um convênio do Estado da Bahia com a Universidade de Columbia que promoveu o estudo de seis comunidades na década de 1950. René Ribeiro, antropólogo pernambucano, que participou de pesquisa da UNESCO sobre relações raciais no Brasil, ${ }^{6}$ escreveu quatro cartas para Dias entre 1954 e 1958. José Loureiro Fernandes escreveu 15 cartas para Dias entre 1952 e 1968. José Loureiro Fernandes era médico e foi um dos fundadores da Faculdade de Filosofia, Ciências e Letras da Universidade Federal do Paraná, tendo dirigido o Departamento de Antropologia desta universidade (Helm 2006: 176). Pertencia ainda ao Departamento de Medicina da Universidade Federal do Paraná quando criou o curso de Estudos Portugueses naquela universidade. A interação entre José Loureiro Fernandes e Jorge Dias dá-se em grande medida pelo interesse deste último em formar o Centro de Estudos Portugueses no Paraná.

5 É importante referir Charles Wagley, pois embora este seja americano e não apareça nas pastas de correspondência de Jorge Dias, é mencionado pelos correspondentes Thales de Azevedo, Florestan Fernandes e Emílio Willems; além disso, os livros de sua autoria sobre pesquisas no Brasil encontram-se com dedicatória para Jorge Dias em sua biblioteca, indicando a relação de Dias com outro intelectual estrangeiro que também transitou pelo Brasil. Como lembrou Roque de Barros Laraia em comunicação oral na 29. ${ }^{a}$ RBA, Wagley, doutor em Columbia e aluno de Franz Boas, esteve no Brasil na década de 1930, tendo sido recebido por Heloísa Alberto Torres, do Museu Nacional no Rio de Janeiro, por onde passaram etnólogos estrangeiros em caminho para suas pesquisas de campo. Realizou pesquisa sobre os índios Apinajé e Tapirapé, estes últimos também estudados por Herbert Baldus. Nascido em 1913, sua relação com o Brasil perdurou até sua morte em 1991, tendo sido considerado um dos primeiros brasilianistas.

6 "Nos anos de 1951 e 1952, a Organização das Nações Unidas para a Educação, Ciência e Cultura (UNESCO) patrocinou uma série de pesquisas sobre as relações raciais no Brasil. As investigações foram desenvolvidas em regiões economicamente tradicionais, como o Nordeste, e em áreas modernas localizadas no Sudeste, tendo em vista apresentar ao mundo os detalhes duma experiência no campo das interações raciais julgada, na época, singular e bem-sucedida, tanto interna quanto externamente" (Maio 1999: 141). 
Manuel Diégues Júnior foi o correspondente com maior número de cartas, tendo enviado 24 missivas durante 20 anos, de 1952 a 1972. Manuel Diégues Júnior nasceu em 1912, em Alagoas. Era professor de Ciências Sociais da PUC-RJ e membro da Comissão Nacional de Folclore, tendo vasta obra publicada no campo da antropologia e dos estudos de folclore. Para além da sua atuação como professor universitário, Manuel Diégues Júnior teve atuação na política cultural do governo na década de 1970.

Darcy Ribeiro, indigenista e muito atuante na área educacional, escreveu apenas uma missiva para Dias em 1956, solicitando apoio para indicação do Marechal Rondon, indigenista, a um prêmio da UNESCO.

Pedro Agostinho, professor da Universidade da Bahia, escreveu duas cartas entre 1969 e 1970.

Alguns dos correspondentes de Dias tiveram papel de destaque no desenvolvimento da antropologia no Brasil. Egon Schaden, José Loureiro Fernandes, Herbert Baldus, Manuel Diégues Júnior e Thales de Azevedo fizeram parte da primeira reunião da Associação Brasileira de Antropologia, ocorrida em 1953. Cinco dos correspondentes de Dias foram presidentes da Associação Brasileira de Antropologia (ABA): José Loureiro Fernandes, Darcy Ribeiro, Herbert Baldus, Thales de Azevedo e René Ribeiro.

Dias correspondeu-se assim com intelectuais que estavam na transição entre os campos da antropologia e dos estudos de folclore, ou então mais identificados com a antropologia, como era o caso dos professores da Escola Livre de Sociologia e Política e da Faculdade de Filosofia, Ciências e Letras da Universidade de São Paulo. Apesar de os estudos de folclore nos anos 60 estarem sofrendo um progressivo afastamento das ciências sociais brasileiras, tratava-se de dois campos em confluência e as cartas indicam esse trânsito e os conflitos entre a antropologia e o folclore no Brasil. Enquanto Diégues informa que Jorge Dias é sócio correspondente da ABA desde 1958, Renato Almeida diz que Dias se ligou ao "nosso Movimento Folclórico" desde $195 \mathrm{l}$ e lhe agradece pela inclusão do tema do folclore nos congressos luso-brasileiros. Vemos, então, o quanto Jorge Dias transitava entre fronteiras disciplinares mais fluidas. Embora não tenhamos tido acesso às cartas de resposta de Jorge Dias, tudo indica que ele tinha conhecimento deste conflito. Em carta de 1969, Pedro Agostinho comenta sobre a animosidade existente entre etnólogos e folcloristas:

"Só lhe digo, por enquanto, é que por cá, folcloristas e etnólogos olham uns para os outros não muito amistosamente. Isto, apesar de o folclore estar institucionalizado oficialmente numa Comissão Nacional de Folclore. Disse apesar, mas na verdade não sei se deveria ter dito por causa de..."

A classificação de intelectuais em relação à proximidade de um ou de outro campo aparece na carta de Thales de Azevedo que, ao recomendar Hildegardes 
Vianna, que iria passar uma temporada no Centro de Estudos de Antropologia Cultural em Lisboa, classifica-a como folclorista.

"Falei nisto com a Sra. Hildegardes Vianna, uma folclorista nossa que pretende passar algum tempo em Lisboa e a quem espero você possa favorecer junto à Fundação Gulbenkian ou ao Comissariado de Alta Cultura, oportunamente, quando ela pleitear a bolsa. É pessoa sem formação sistemática, mas observadora, interessada, séria: cronista mais do que cientista, porém com muito material registrado em seus pequenos trabalhos, e capaz de trazer daí informes e impressões de interesse para o nosso intercâmbio cultural. Hildegardes é, além do mais, pessoa muito bem relacionada em nossos grupos do Instituto Histórico, da Comissão de Folclore, e pessoa de uma personalidade comunicativa, simples, séria. Vocês gostarão dela, se for a Portugal".

O fato de Jorge Dias corresponder-se com autores mais ou menos próximos ou distantes dos campos da antropologia e do folclore não significa que a forma de tratamento fosse igual para todos. O que pode ser observado na relação de Dias com estes intelectuais brasileiros é que, embora houvesse trocas de homenagens, conforme veremos adiante, com intelectuais dos estudos de folclore, como Renato Almeida, a busca de uma troca intelectual ocorre mais com correspondentes ligados à ELSP ou à FFCL-USP e com antropólogos ligados a outras universidades. Para Florestan Fernandes, por exemplo, Jorge Dias solicitou uma palestra, a ser redigida para o colóquio em Metodologia das Ciências Sociais, no Centro de Estudos Políticos e Sociais da Junta das Missões Geográficas e de Investigações do Ultramar, em Lisboa. Ficaria a cargo do próprio Jorge Dias a leitura do texto. Nesta carta, de 1956, Jorge Dias diz: "Como você tem uma série de lições sobre o método Empírico e Indutivo, eu pensei que não lhe roubaria muito tempo escrever umas páginas sobre este assunto". Continua a carta mencionando a origem portuguesa de Fernandes e a intenção de que seu trabalho se tornasse mais conhecido em Portugal: "Era uma maneira de pagar uma dívida a este país de que você ancestralmente provém, e tornar-se mais conhecido entre nós".

Com Egon Schaden ocorre uma troca de publicações: Dias escreveu um artigo para a Revista de Antropologia (Dias 1955a), da qual Schaden era editor, e diz que escreverá uma resenha sobre o livro de Schaden (1954) - o que afinal não ocorre -; Schaden fará publicar uma resenha na Revista de Antropologia (Mussolini 1956) sobre o livro Rio de Onor (Dias 1953). Em carta de 1955, expressa Schaden: "Fiquei muito satisfeito ao saber que você pretende fazer uma recensão crítica ao meu livro sobre a cultura guarani. De minha parte, posso comunicar-lhe que dentro em breve a Revista de Antropologia trará um pequeno estudo sobre o magnífico 'Rio de Onor' ". 
Embora a maioria dos correspondentes ligados aos estudos de folclore pedisse sugestões para Dias sobre bibliografia e sua opinião sobre seus trabalhos, a recíproca não ocorria - com exceção de Cascudo. Câmara Cascudo em carta de 1952, comenta o trabalho de Dias "Sacrifícios simbólicos associados às malhas" (1951) e, em carta de 1954, o livro Rio de Onor (Dias 1953). Os trechos em que Cascudo comenta estes trabalhos estão sublinhados a lápis, mostrando que provavelmente a opinião de Cascudo era importante para Dias, talvez pelo conhecimento enciclopédico de Cascudo sobre tudo o que se refere à cultura popular brasileira e suas origens portuguesas.

\section{INTERCÂMBIOS BRASILUSOS}

Além das trocas intelectuais, ocorreram trocas de contatos, homenagens, indicações de emprego, objetos e fotografias.

Diégues, em carta de 1952, pede a Dias que lhe mande a indicação de algumas pessoas a quem ele possa enviar seu livro Etnias e o Engenho de Açúcar.

Os convites e as propostas para que Jorge Dias fosse ao Brasil fizeram parte das correspondências de Manuel Diégues Júnior e de José Loureiro Fernandes. Em duas cartas de 1961, Diégues insiste para que Jorge Dias passe uma temporada no Brasil como expert da UNESCO. Em 1971, Diégues convida-o para dar um curso no mestrado em Antropologia Social do Museu Nacional. Jorge Dias parece um pouco hesitante por questões de saúde, conforme o que aparenta ser um rascunho de sua carta. No final, a proposta não se concretiza por suspensão da contratação de professores estrangeiros naquele período.

As cartas de Loureiro Fernandes indicam o seu esforço de articulação para que Jorge Dias ministre aulas na Universidade do Paraná. Fernandes vai a Portugal em 1952 com o intuito de estabelecer convênios entre as universidades portuguesas e a Universidade do Paraná e refere-se a si próprio como o encarregado da missão de promover este intercâmbio, em carta de 1952:

"Por esse trecho da carta do Reitor que transcrevi acima, vê você que as coisas vão bem e que as relações de intercâmbio cultural entre as Universidades Portuguesas e a Universidade do Paraná, tarefa da qual quero ser um dos humildes obreiros, vae em muito bom caminho".

Em 1954, Fernandes inicia as primeiras reuniões para a criação do Centro de Estudos Portugueses na Universidade do Paraná. Além do interesse pela cultura portuguesa, Fernandes tem a expectativa de que Dias possa fazer trabalho de campo junto aos suábios, população de origem alemã que se estabeleceu numa colônia agrícola no Paraná depois da II Guerra Mundial. Ao sentir a dificuldade em obter recursos locais para financiar a pesquisa, ele sugere que esta seja financiada por um convênio Capes/UNESCO. Aparentemente, essa 
pesquisa não se concretizou, embora Dias tenha demonstrado grande interesse pelo tema ao escrever o artigo "Um caso de colonização modelo" (1993 [1966]), publicado em Lisboa com dados gerais sobre aquela colônia.

As correspondências que versam sobre a troca de objetos estão relacionadas à constituição de acervos museológicos. Jorge Dias estava, desde 1959, montando o Museu de Etnologia e Diégues Júnior diz em carta estar se esforçando para enviar peças da cultura popular do Brasil atual para lá. $\mathrm{Na}$ correspondência de José Loureiro Fernandes também é mencionada a possibilidade de intercâmbio de objetos e fotografias brasileiros para o Museu de Etnologia, e fotografias portuguesas para o Museu de Arqueologia e Artes Populares, em Paranaguá, que Fernandes está organizando e que seria inaugurado em 1962.

"Poderia então mandar-lhe algumas peças indígenas pela Embaixada e você enviar-me-ia peças etnográficas portuguesas ou africanas. Como prova do meu desejo de intercâmbio, mando-lhe oito fotografias dos índios Xetá, sobre os quais já lhe falei, bem como aos seus colaboradores, uma Separata... O Departamento de Antropologia da Universidade do Paraná gostaria de receber, em permuta, fotografias de artesões portugueses fazendo cestos, trabalhando com cerâmica, tecendo no tear, fiando etc. Interessaria muito uma boa fotografia de fiandeira, na qual se pudesse ver a maneira de manter a roca e trabalhar o fuso".

Fernandes deixa clara a expectativa de reciprocidade nesta troca de objetos e fotografias: "Como vê, vou ajudar o colega lusitano, mas espero retribuição". $\mathrm{O}$ interesse de Fernandes quanto ao entrelaçamento das culturas portuguesas e brasileiras parece dar-se sobretudo em relação à cultura material, no que encontra afinidades com o trabalho de Dias, voltado para a cultura popular portuguesa, na qual investiga sobretudo os objetos materiais (Leal 2000: 50).

Entre Renato Almeida e Jorge Dias podemos observar a ocorrência de uma troca de homenagens. Almeida, em carta de 1955, informa que propôs o nome de Dias para receber a Ordem do Cruzeiro do Sul, homenagem do governo brasileiro. "Espero que o meu Governo em breve reconheça tudo isso como deve”. A condecoração ocorre em 1956. Em carta de 1958, Almeida diz que vai propor o nome de Jorge Dias para o recém-criado prêmio Silvio Romero, referindo-se a ele como "a condecoração dos folcloristas". Em carta de 1961, solicita a Dias um artigo para a Revista Brasileira de Folclore: "peço fazendo disso grande questão. [...] Estimaria muito que o primeiro artigo, não ouso dizer de estrangeiro, porque não o considero tal, mas de personalidade não brasileira, fosse o seu. [...] No meio do mundo de suas atividades, só ouso pedir-lhe o artigo no crédito da amizade". Dias escreve então "A lenda das Amazonas" para a revista (1962). 
Jorge Dias organiza um livro em homenagem a Renato Almeida, publicado em 1960. São convidados tanto brasileiros quanto estrangeiros. Além disso, Dias indica o nome de Almeida para a CIAP, o que muito agradou a este. Depois, no entanto, em carta de 1958, mostra-se menos entusiasmado com a CIAP, pois, apesar de ter sido eleito membro, nunca mais tivera notícias dela. Em carta de 1964, lamenta a exclusão de latino-americanos desta organização. "Leio com melancolia a reorganização da CIAP, com a ausência de qualquer sul-americano, quando estamos trabalhando tão ativamente".

Em relação ao livro Estudos e Ensaios Folclóricos em Homenagem a Renato Almeida (Dias 1960), parece também haver a expectativa de que Jorge Dias possibilite mais contatos internacionais aos brasileiros. Almeida sugere nomes, em carta de 1956: "Se fosse possível você pedir ainda que o Marinus e o Stith Thompson mandassem algo, ficar-lhe-ia agradecido, por se tratarem de mestres e de amigos meus".

Maria de Lourdes Borges Ribeiro, ligada à Comissão Paulista de Folclore, e que estava na organização do livro já no ano anterior, 1955, mostra-se preocupada com a ausência de alguns autores estrangeiros: "Estranhamos a ausência do Boggs, do Marinus, da Miss Maud Karpeles, do H. Rivière, do Stith Thompson, sobretudo dos três primeiros que são grandes amigos do Renato..." Ao final, Ralph Steele Boggs e Maud Karpeles efetivamente contribuíram com artigos.

Já para os brasileiros, participar do livro em homenagem a Renato Almeida tem outro significado. Mariza Lira reclama de uma possível exclusão de colaboração neste livro - por fim, seu artigo acabou fazendo parte do livro. Em carta de 1955, queixa-se com Dias:

"O que não desejava era deixar de homenagear o Renato. Quase toda a Comissão recebeu convite e a minha exclusão deixou-me no rol dos não 'especialistas'. Embora já não faça muita questão do julgamento, mesmo do Papa, sentindo-me uma estudiosa do folclore e não vendo aqui no Brasil nada além de mim que Joaquim Ribeiro, Câmara Cascudo, Silvio Julio, isso só para falar na presente geração fiquei sentida. Não devia, mas foi o Joaquim mesmo quem me insuflou neste caso".

É possível que Renato Almeida tivesse a expectativa de que Jorge Dias alargasse seus contatos internacionais. Leal (2000) analisa a diferença de Dias em face de outros etnógrafos portugueses do mesmo período. Dias buscou estabelecer redes de contatos fora de Portugal, tanto no Brasil quanto na Europa e nos Estados Unidos.

A leitura atenta destas cartas demonstra que Dias circulou no campo intelectual das ciências sociais brasileiras num momento em que este estava ainda em formação e os estudos de folclore ainda eram próximos daquele. Contudo, 
Dias parece ter percebido esse processo de distanciamento entre estes dois campos, e fez distinções entre os dois campos ao realizar trocas intelectuais principalmente com aqueles ligados às ciências sociais em sua forma mais acadêmica. Especialmente em relação a Florestan Fernandes, que buscava construir o campo acadêmico das ciências sociais no Brasil, Dias parece ter mostrado especial deferência querendo que seu trabalho fosse conhecido em Portugal.

\section{A BUSCA DE CONTINUIDADES NOS DOIS LADOS DO ATLÂNTICO}

A noção da continuidade cultural entre Portugal e Brasil alimenta alguns dos projetos de intercâmbio entre Dias, José Loureiro Fernandes, Renato Almeida, Manuel Diégues Júnior, Thales de Azevedo e Emílio Willems. Estes autores compartilham a ideia de que a temática dos paralelismos culturais brasileiros e portugueses deve fazer parte de uma agenda de pesquisas. Na década de 1950 , Dias parecia bem entusiasmado com a possibilidade de pesquisadores brasileiros se juntarem a pesquisadores portugueses para estudarem estas semelhanças culturais.

"O Brasil dispõe hoje de uma plêiade numerosa de investigadores excelentemente bem preparados que atacam as questões com afinco e saber e prometem um futuro glorioso à ciência do seu país. Se reunirmos esforços, é de crer que dentro em breve se tenham feito grandes progressos neste campo de saber tão promissor (Dias 1955b: 153)".

Ao comentar o recebimento do trabalho de Dias sobre Vilarinho da Furna (1948), ${ }^{7}$ Manuel Diégues Júnior aponta os paralelos entre o folclore brasileiro e o português: "Veja você que surpresas nos proporcionam estudos folclóricos e etnográficos quando chegamos a estas comparações". Em carta de 1956, ele comenta ainda: "apesar das diversidades apresentadas, se mantém a unidade sonhada e desejada na colonização com a base cultural lusitana". Ainda em outra carta de 1969, Diégues reforça sua opinião sobre a forte influência lusa na cultura brasileira e a necessidade de estudá-la: "Cada vez acredito mais que seria indispensável, para portugueses e brasileiros, um estudo sobre a permanência dos valores lusos em várias áreas, sua adaptação e suas transformações, o que nos daria um retrato do que éramos e do que estamos sendo".

Nas primeiras cartas de Diégues, ainda na década de 1950, ele pede sugestões a Dias para os seus cursos na Pontifícia Universidade Católica do Rio de

7 O livro de Dias Vilarinho da Furna: Uma Aldeia Comunitária é a ampliação de sua tese de doutorado, defendida em Munique em 1944 sobre uma aldeia comunitária de atividade agro-pastoril no Norte de Portugal. 
Janeiro sobre Etnografia do Brasil. Ele envia seu programa de curso para Jorge Dias e, em carta de 1954, solicita os seus programas dos cursos de Etnografia e Etnografia Portuguesa. Em carta de 1955, Diégues pede bibliografia e sugestões a respeito do português enquanto grupo étnico. Como Diégues, Loureiro Fernandes também vê ligações entre a cultura brasileira e o legado luso que precisam ser pesquisadas e salvaguardadas. Em carta de 1952, ele diz:

"Por outro lado, poderíamos programar um curso de etnografia no qual o meu amigo ministrar-nos-ia os seus conhecimentos especializados de Etnografia Portuguesa, muito útil seria, para preparar as nossas gerações para o nobre labor de salvar todo um patrimônio de valores tradicionais que, através do elemento luso, aqui chegou e por vezes transformou-se, dando-nos problemas etnográficos regionais para cujas soluções necessitamos de valores portugueses".

Fernandes vê em risco a cultura portuguesa no Brasil e considera que para resguardá-la é necessário o seu estudo com o auxílio dos próprios portugueses.

"Cabe agora aos nossos amigos portugueses auxiliarem-nos na tarefa, que eu considero de profundo significado, pois creio que em nenhuma região do Brasil, como Santa Catarina e Paraná, a cultura portuguesa perdeu tanto da sua primitiva influência, ou melhor, significação. Entretanto, o amigo viu que na realidade esse fundo sobrevive de modo notável em todo o Estado. Precisamos valorizá-lo à luz dos estudos".

Em estados do Sul do Brasil, como Santa Catarina, houve ainda maior preocupação com a busca de origens portuguesas do que em outras regiões, pela parte de estudiosos do campo dos estudos de folclore, da antropologia e da história. ${ }^{8}$

Renato Almeida, em carta de 1958, opina a favor de um estudo sistemático dos "elementos lusos" no folclore brasileiro. Segundo ele, o que até então se via eram estudos livrescos, quando seriam necessários estudos antropológicos.

Emílio Willems, em carta de 1949, demonstra seu interesse pelo livro Vilarinho da Furna (1948), que lhe fora enviado por Dias. Nesta carta, Willems

8 No âmbito dos estudos de folclore, é do contato entre intelectuais de Santa Catarina e do arquipélago dos Açores que emerge de forma mais sistemática o interesse pela cultura portuguesa. Em seu trabalho Cultura e Identidade Açoriana: O Movimento Açorianista em Santa Catarina, Leal (2007) retoma $\mathrm{o}$ interesse de intelectuais catarinenses pelas origens açorianas do estado. A colonização açoriana do estado de Santa Catarina remonta ao século XVIII; no entanto, com a chegada de imigrantes europeus de outras origens ao estado no século XX, houve uma relativa desvalorização desta herança. Foi apenas em 1948, com a realização do $1 .{ }^{\circ}$ Congresso Catarinense de História, que intelectuais catarinenses e alguns gaúchos passaram a se voltar para a herança açoriana do estado. 
expressa a razão de seu interesse pelo livro e o seguinte trecho encontra-se sublinhado a lápis por Dias: "pois meu atual plano de pesquisa visa o estudo de elementos culturais portugueses que se conservaram, puros ou modificados, na 'folk culture' do Brasil". Willems tem ainda o plano de passar alguns meses em Portugal para continuar a pesquisar o tema, e como não conseguiu verba para isto no Brasil tem a expectativa de conseguir financiamento junto à Universidade de Vanderbuilt, nos Estados Unidos, onde está dando aulas. Pretende escrever um paper sobre a cultura portuguesa no Brasil e pede indicações de bibliografia a Dias sobre a organização das comunidades e particularmente da família portuguesa. Em carta de 1953, indaga a Dias: "A pergunta principal que gostaria de fazer-lhe é naturalmente esta: a que ponto os fatos observados no Brasil se aplicam à família portuguesa?" 9 Desta forma é interessante observar que este autor, cujo principal interesse de pesquisa, quando residiu no Brasil, foi o tema da aculturação de comunidades de origem alemã, tenha também aplicado a questão da aculturação ao estudo da cultura portuguesa no Brasil.

Além do interesse pelos grupos de origem alemã no Brasil, Emílio Willems dedicou-se também a estudos de comunidades ${ }^{10}$ interesse compartilhado ainda por outro correspondente de Dias, Thales de Azevedo. O interesse pelo tema da cultura portuguesa no Brasil atravessa os estudos de comunidade no caso de Willems e Thales. Em carta de 1950 Willems menciona: "Num seminário discutimos a cultura de Cunha [nome fictício de uma das comunidades estudadas por Willems] e a de uma comunidade amazônica que [Charles] Wagley estudou alguns anos atrás... Diria que o denominador comum é sempre o background 'português'". Em carta de 1957, Thales de Azevedo menciona a possibilidade de Dias realizar pesquisa numa comunidade de origem portuguesa isolada na Bahia: "Uma das possibilidades nossas é a de excursões [...] onde existem velhas povoações de origem portuguesa ainda muito isoladas e pouco modificadas pelo tempo".

Conforme podemos observar, os correspondentes de Dias estavam às voltas com a ideia da continuidade cultural e da preservação da cultura portuguesa no Brasil, de tal forma que aparece nas correspondências a ideia de que o português não seria um estrangeiro para o brasileiro. Em uma carta de 1952, respondendo ao estranhamento de Dias a respeito do fato de não ter incluído em seu livro Etnias e Culturas os portugueses entre "grupos estrangeiros imigrados", Diégues responde que não considera os portugueses estrangeiros.

9 Willems publicou em 1955 o artigo "A família portuguesa contemporânea" na revista brasileira Sociologia.

10 Com influência da sociologia americana, os estudos de comunidades tiveram presença importante nas ciências sociais brasileiras durante as décadas de 1940 a 1960, exercendo um papel importante na institucionalização daquelas no Brasil. Tais estudos investigavam o processo de mudança social em pequenas comunidades e sofreram críticas por não levarem em conta estruturas sociais englobantes que atingiam essas comunidades (Oliveira e Maio 2011). 
Também Renato Almeida, quando de seu pedido de um artigo de Dias para a Revista Brasileira de Folclore, diz que não o considera estrangeiro. No entanto, por outro lado, em cartas que tratavam menos de agendas de pesquisa e mais de esferas de relacionamento de trabalho, aparecem algumas considerações sobre a diferença de temperamento entre brasileiros e portugueses, colocando em cheque a ideia de continuidade.

Hildegardes Vianna menciona o que seria uma diferença de temperamento entre portugueses e brasileiros. Após ter passado uma temporada em Portugal junto a Jorge Dias e sua equipe no Centro de Antropologia Cultural, Hildegardes, em carta a Dias, de 1972, reclama da formalidade dos portugueses: "Não gostei de você me chamar de Excelentíssima Professora Hildegardes. Mas como sei que vocês portugueses não conseguem ser como nós brasileiros, descontraídos, perdoo o delito desta vez. Tá?"

Florestan Fernandes, em suas cartas a Diégues Júnior, reflete em tom irônico sobre suas origens portuguesas ao reclamar, em carta de 1956, sobre suas condições de trabalho na universidade: "Como português de segunda geração sou um pouco lamuriento, mas a verdade é essa: só me sinto infeliz quando tento levar a vida à minha maneira". Desta forma há uma diferença entre a visão sobre a continuidade cultural entre Portugal e o Brasil enquanto projeto de pesquisa e essa mesma visão no que se refere ao relacionamento interpessoal; neste segundo caso, prevalece um estereótipo do português enquanto um tipo de caráter mais fechado enquanto que o brasileiro seria um tipo de caráter mais aberto. Essa diferença de visão entre, por um lado, a ideia de que há uma continuidade cultural entre Portugal e Brasil que deve ser pesquisada e, por outro, a ideia de temperamentos distintos entre portugueses e brasileiros nos leva a perguntar sobre o que era visto como continuidade e o significado desta agenda de pesquisas para as duas antropologias, a portuguesa e a brasileira.

Stocking Jr. (1982) analisa motivações diferentes para a antropologia desenvolvida em países centrais e para aquela desenvolvida em países mais periféricos. A antropologia internacional seria assim a antropologia euro-americana, nascida junto com o imperialismo e definida pelo estudo do outro externo, não europeu, constituindo-se numa antropologia de empire building (Stocking Jr. 1982: 173). A antropologia periférica, desenvolvida seja em ex-colônias, cujos nativos foram foco de estudos antropológicos, seja em contextos metropolitanos secundários, teria como característica dominante a problemática da construção da nação, num processo de nation building. A alteridade, neste caso, é majoritariamente interna (Stocking Jr. 1982: 179).

No caso dos estudos de folclore e da antropologia brasileira podemos entender a busca de continuidades culturais entre Portugal e o Brasil como uma das formas de construção da nacionalidade junto com outras, como o estudo do índio e do negro. Para Peirano (1981), uma característica da antropologia brasileira foi o fato de estar voltada às questões da nação. Desta forma, pelo 
lado da sociologia, com Florestan Fernandes, havia a tentativa de se formular uma teoria feita no Brasil e a busca de soluções para os problemas nacionais. Em relação à etnologia indígena, também ocorre essa orientação quanto à problemática da construção da nação. Peirano analisa como a etnologia dos povos ameríndios indígenas feita por antropólogos brasileiros era diferente daquela realizada por antropólogos estrangeiros no Brasil. Enquanto estes últimos estudavam as comunidades indígenas como entidades isoladas da sociedade nacional, aqueles buscavam estudar as relações entre os indígenas e a sociedade nacional. Exemplar nessa direção seria a elaboração do conceito de fricção interétnica, cunhado por Roberto Cardoso de Oliveira no Processo de Assimilação dos Terêna (1960), justamente para dar conta do que seriam os conflitos entre os grupos indígenas e a sociedade mais ampla. Para este autor, tal conflito equivaleria ao da luta de classes interna à sociedade de classes nacional (apud Peirano 1981: 97).

Em relação à antropologia portuguesa, é interessante examinar se, no interesse de pesquisa que Jorge Dias e outros intelectuais portugueses tiveram pelo Brasil, teria prevalecido uma antropologia do tipo empire building ou nation building.

Leal (2000) postula que a antropologia portuguesa esteve, paradoxalmente (por ser já um país consolidado desde o século XII), voltada para o nation building, onde a pesquisa da cultura popular, enquanto locus da nacionalidade, teve papel fundamental. Este autor considera que a antropologia portuguesa desenvolvida entre 1870 e 1970 volta-se, sobretudo, à cultura popular de matriz rural. Jorge Dias e sua equipe, como mostra Leal (2000), também estiveram voltados para a pesquisa da cultura material do campesinato português. Já Susana Viegas e João de Pina-Cabral (2014) discordam desta posição, considerando que as dimensões de empire building e nation building na antropologia portuguesa estiveram inter-relacionadas. Na Europa Continental não haveria, na opinião destes autores, a separação radical que ocorreu na Inglaterra entre o projeto etnológico (de construção da nação) e o projeto antropológico (de construção do império). Conforme mostram esses autores, em meados do século XX, no período ditatorial de Salazar, a antropologia portuguesa pendeu para um viés de construção do império e a visão sobre os nativos portugueses e das colônias era de continuidade, expressando a não separação radical entre as duas antropologias: "Esta continuidade entre o mundo 'tradicional' português e o dos nativos do império é expressa por Galvão tal como por muitos antropólogos do período, quer os que eram a favor, quer os que eram contra o regime ditatorial..." (Viegas e Pina-Cabral 2014: 318). Ainda para estes autores, a própria condição de país imperial foi fundamental para a existência do projeto português de nação (2014: 314), como aconteceu com o lusotropicalismo, uma ideologia de inspiração em Gilberto Freyre que justificava a manutenção, tardia, de colônias africanas por parte de Portugal nos últimos 15 anos 
do período salazarista (2014: 319). Também no caso da antropologia física, como demonstra Roque (2010) em sua reconstituição da trajetória de crânios humanos da antiga colônia portuguesa de Timor até instituições científicas em Coimbra, há uma coexistência entre construção da nação e construção do império. Mesmo Leal (2006b) contemporiza a questão do império, demonstrando como a posição de Portugal enquanto país imperial aparecia de forma escondida no pensamento de variados antropólogos portugueses.

Acreditamos que, para o caso específico sobre o qual estamos debruçando nossa análise, a ideia de império escondido ajuda a compreender a busca de continuidades culturais entre o Brasil e Portugal. ${ }^{11}$

Para Leal (2006b), uma das formas em que a noção de império aparecia sorrateiramente estava nas obras daqueles autores que trabalhavam com a ideia de uma psicologia étnica portuguesa, como era o caso de Dias. "Para eles, a existência da nação assentava numa 'alma ou mentalidade nacionais', que derivavam fundamentalmente da cultura popular e que refletiriam uma maneira de ser específica dos portugueses" (Leal 2006b: 70). Dias concebia a cultura portuguesa como composta por áreas culturais várias que tendiam para uma unidade em meio à diversidade de costumes. Essa unidade era o próprio caráter nacional português. Influenciado pela Escola Americana de Cultura e Personalidade, ele enxergava uma personalidade em Portugal enquanto nação, considerando que um dos atributos do caráter nacional português era a capacidade de adaptação. Haveria na antinomia "sonhador" e "homem de ação" a explicação para a expansão ultramarina portuguesa (Leal 2006b: 73). Dessa forma, a noção de Império português aparece no próprio caráter adaptativo do português, que o ajudaria a ser bem-sucedido na colonização de terras distantes.

Os artigos de Dias escritos na década de 1950 demonstram o interesse em entender a formação cultural brasileira como uma extensão da portuguesa. Além disso, na forma como Dias pensava o Brasil, estava explicitada a ideia de que este país fez outrora parte do Império português. Ele pergunta no artigo sobre a área cultural luso-brasileira que estudos sistemáticos são necessários além da língua: "haverá mais elementos de cultura espiritual e social

I1 Vale ainda destacar que este empreendimento de busca de continuidades entre Portugal e Brasil estava na agenda das políticas culturais do governo de Salazar. Bettencourt, que chefiava a seção brasileira do Secretariado de Informações de Portugal, em seu artigo "Folclore do Brasil", fala sobre isso: "Que por nosso lado, isso não será difícil basta o fato - que queremos recordar - de ter sido a reunião preparatória que em Portugal se realizou para concretizarem-se as finalidades e os assuntos a serem estudados no $1 .{ }^{\circ}$ Congresso Luso-Brasileiro de Folclore, realizado sob os auspícios do Secretariado Nacional de Informação, Cultura Popular e Turismo, cujo diretor então, António Ferro, ao elaborar o Acordo Cultural de 1941, se não esqueceu de incluir num dos seus capítulos, como uma das suas obrigações: 'O estudo do folclore luso-brasileiro através de publicações editadas pelos dois Organismos e da realização de festas populares e tradicionais comuns aos dois países'” (Bettencourt 1960: 419; grifos nossos). 
partilhados igualmente por uma maioria de brasileiros e portugueses?" (Dias 1955b: 151). Esta dúvida advém do fato de que, embora Dias considere o Brasil um caso de transplantação da cultura portuguesa através do oceano, o ambiente e a influência de outras culturas deram origem a uma nova realidade: "a florescente cultura brasileira". Por fim, Dias aponta que, embora se deva falar em duas áreas culturais distintas, a brasileira e a portuguesa, os elementos comuns característicos de uma mesma área cultural permanecem:

"Contudo, não é menos verdade que existe uma cultura luso-brasileira, na medida em que essa cultura apresenta afinidades de comportamento humano e de padrões culturais que, sendo comuns a portugueses e brasileiros, faltam ou apresentam outro significado nas culturas vizinhas" (1955b: 151).

Essas afinidades estariam presentes em vários aspectos, como comportamento em relação à família, religião, preconceito racial (sua ausência), cultura material, folclore e formas de diversão (Dias 1955b). Já no artigo "Paralelismo no processo de formação das nações" (1993 [1956]), Dias expõe sua opinião a respeito da formação cultural brasileira e sua proximidade com Portugal de forma mais assertiva, percebendo a história brasileira como homóloga da história portuguesa:

"Que haverá de comum entre essa unidade nacional homogênea que é Portugal e o Brasil, que, como vimos, se está formando pela combinação e assimilação de tantos elementos diversos? Há muito! A identidade pode mesmo dizer-se que é perfeita. Portugal histórico representa o fim de um ciclo de formação posterior que é praticamente a repetição do processo de formação brasileira de que atrás falamos" (Dias 1993 [1956]: 127).

Essa forma de enxergar o Brasil como uma continuidade da cultura portuguesa, mesmo com influências externas, talvez se explique em função da visão difusionista particular de Dias. Como aponta Leal, "O difusionismo em Jorge Dias é nesse sentido um difusionismo ideologicamente sobredeterminado, na medida em que não é apenas uma aplicação acadêmica de ideias sobre história e origens, mas é também um instrumento identitário para enraizar a nação na longa duração da história" (2014: 138). Assim, o Brasil seria visto como um exemplo de expansão do caráter nacional português, na medida em que a colonização permitiu a difusão da cultura portuguesa, e em alguma medida apesar de outros elementos miscigenadores - a sua continuidade alhures. 


\section{CONCLUSÃO}

A análise das correspondências recebidas por Jorge Dias contribui para a compreensão de um determinado período das ciências sociais brasileiras e das relações estabelecidas entre duas antropologias, a brasileira e a portuguesa, bem como os interesses temáticos compartilhados por ambas.

Dias, em seu contato com intelectuais brasileiros, encontrou uma rede de estudiosos de folclore bastante atuantes e sociólogos e antropólogos brasileiros envolvidos com estudos de comunidade e relações raciais. Tratava-se de um período, que vinha desde a década de 1930 , em que o país era um ponto de passagem para intelectuais estrangeiros que aqui realizaram pesquisas (Corrêa 2000). Foi também um tempo de progressivo afastamento entre as ciências sociais e os estudos de folclore e Dias não esteve alheio a este processo, tendo sido recrutado por ambos os lados para participar em disciplinas em formação, como a antropologia e os estudos de folclore, que disputavam espaço e legitimidade no ambiente universitário. A relação com Dias significava também, para estes intelectuais, uma forma de maior inserção na Europa, através da possibilidade, dentre outras coisas, de publicação e divulgação de suas obras em Portugal, contribuindo para o ganho de prestígio do intelectual e da disciplina.

A temática das origens portuguesas da cultura brasileira foi outro importante fator motivador na relação estabelecida entre Dias e os intelectuais brasileiros. Embora houvesse um afastamento entre os estudos de folclore e as ciências sociais, no período estudado esta busca da construção da nacionalidade atravessava ambos os campos. Não fez parte do escopo deste artigo discutir o peso das dimensões de empire building e nation building na história do desenvolvimento da antropologia em Portugal, mas ater-nos à análise das temáticas compartilhadas entre Dias e os intelectuais brasileiros. Nesse sentido, acreditamos que ambos os lados estavam orientados por noções de nation building: do lado brasileiro, pela motivação de reforçar o imaginário sobre origens portuguesas da cultura brasileira; no caso de Dias, devido ao interesse pela continuidade da cultura popular portuguesa na antiga colônia. A troca de objetos para constituição de acervos museológicos - a obtenção de objetos da cultura popular portuguesa por parte de Fernandes e objetos da cultura popular brasileira e indígenas por parte de Dias - é reveladora dessa busca de constituição de uma continuidade cultural dos dois lados do Atlântico, na medida em que os museus, ao colecionarem e exporem objetos, são parte de processos de construção de culturas e subjetividades de grupos (Clifford 1988; Handler 1985). Nesse sentido, a constituição destes acervos cria uma representação de origens portuguesas da cultura brasileira, no caso do Brasil, e de expansão imperial portuguesa, no caso de Portugal. Assim, se no caso dos intelectuais brasileiros a dimensão de nation building é mais clara, no caso de Dias é 
mais ambígua. Tal ambiguidade ocorre na medida em que a noção de Império aparece de forma mais sorrateira, como no caso da busca de objetos indígenas para serem expostos no Museu Nacional de Etnologia em Portugal e na forma de pensar a continuidade cultural portuguesa. Esta é pensada enquanto uma faceta do caráter português que teria facilidade de se adaptar em terras distantes.

\section{BIBLIOGRAFIA}

ARRUDA, Maria Arminda do Nascimento, 1998, “Trajetória singular: o acadêmico Florestan Fernandes”, em P.H. Martinez (org.), Florestan ou o Sentido das Coisas. São Paulo, Centro Universitário Maria Antonia, Boitempo Editorial, 167-188.

BETTENCOURT, Gastão, 1960, "Folclore do Brasil", em J. Dias (org.), Estudos e Ensaios Folclóricos em Homenagem a Renato Almeida. Rio de Janeiro, Ministério das Relações Exteriores, 399-422.

CAVALCANTI Maria Laura Viveiros de Castro, e Luiz Rodolfo da Paixão VILHENA, 2012, “Traçando fronteiras: Florestan Fernandes e a marginalização do folclore", em M.L. V.C. Cavalcanti (org.), Reconhecimentos: Antropologia, Folclore e Cultura Popular. Rio de Janeiro, Aeroplano, 102-147.

CIACCHI, A., 2015, "Do desembarque do navio ao embarque na canoa: Gioconda Mussolini, 1886-1938”, Revista de Antropologia, 58: 69-98.

CLIFFORD, James, 1988, The Predicament of Culture: Twentieth-Century Ethnography, Literature and Art. Cambridge, MA, Harvard University Press.

CORRÊA, Mariza, 1988, "Traficantes do excêntrico: os antropólogos no Brasil dos anos 30 aos anos 60", Revista Brasileira de Ciências Sociais, 6 (3): 79-98.

CORRÊA, Mariza, 2000, "O mistério dos orixás e das bonecas: raça e gênero na antropologia brasileira”, Etnográfica, IV (2): 233-265.

DIAS, Jorge, 1948, Vilarinho da Furna: Uma Aldeia Comunitária. Porto, Centro de Estudos de Etnologia Peninsular.

DIAS, Jorge, 1951, "Sacrifícios simbólicos associados às malhas", Terra Lusa, 1: 145-148.

DIAS, Jorge, 1953, Rio de Onor: Comunitarismo Agro-Pastoril. Porto, Instituto de Alta Cultura. DIAS, Jorge, 1955a, "Algumas considerações acerca da estrutura social do povo português", Revista de Antropologia, 3 (1): 1-20.

DIAS, Jorge, 1955b, "Algumas considerações sobre áreas culturais: a área cultural luso-brasileira", Revista de Guimarães, LXV (I-II): 145-153.

DIAS, Jorge (org.), 1960, Estudos e Ensaios Folclóricos em Homenagem a Renato Almeida. Rio de Janeiro, Ministério das Relações Exteriores.

DIAS, Jorge, 1962, "A lenda das Amazonas", Revista Brasileira de Folclore, 2: 17-23.

DIAS, Jorge, 1993 [1956], "Paralelismo no processo de formação das nações", em J. Dias, Estudos de Antropologia. Lisboa, Imprensa Nacional Casa da Moeda, 119-134. 
DIAS, Jorge, 1993 [1966], “Um caso de colonização modelo”, em J. Dias, Estudos de Antropologia, vol. II. Lisboa, Imprensa Nacional Casa da Moeda, 317-332.

HANDLER, Richard, 1985, "On having a culture: nationalism and the preservation of Quebec's Patrimoine", em G. Stocking (org.). Objects and Others: Essays on Museums and Material Culture. Wisconsin, The University of Wisconsin Press, 192-217.

HELM, Cecília Maria Vieira, 2006, “Os cinquenta anos da ABA no Paraná”, em E. Godoi e C. Eckert (orgs.), Homenagens: Associação Brasileira de Antropologia, 50 anos. Blumenau, Nova Letra, 175-183.

LEAL, João, 2000, Etnografias Portuguesas (1870-1970): Cultura Popular e Identidade Nacional. Lisboa, Publicações Dom Quixote.

LEAL, João, 2006a, Antropologia em Portugal: Mestres, Percursos e Transições. Lisboa, Livros Horizonte.

LEAL, João, 2006b, "O império escondido: camponeses, construção da nação e império na antropologia portuguesa", em M.R. Sanches (org.), "Portugal Não é Um País Pequeno": Contar o "Império" na Pós-Colonialidade. Lisboa, Livros Cotovia, 63-79.

LEAL, João, 2007, Cultura e Identidade Açoriana: O Movimento Açorianista em Santa Catarina. Florianópolis, Editora Insular.

LEAL, João, 2014, "Usos da história em Jorge Dias", em Clara Saraiva, Jean-Yves Durand e João Alpuim (orgs.), 2014, Caminhos e Diálogos da Antropologia Portuguesa: Homenagem a Benjamim Pereira. Viana do Castelo, Município de Viana do Castelo, 135-146.

LUPI, João Eduardo, 1984, A Concepção da Etnologia em António Jorge Dias. Braga, Publicações da Faculdade de Filosofia.

MAIO, Marcos Chor, 1999, "O projeto Unesco e a agenda das ciências sociais no Brasil dos anos 40 e 50", Revista Brasileira de Ciências Sociais, 14 (41): 141-158.

MATOS, Patrícia Ferraz de, 2011, "A vida e a obra do Professor Mendes Correia (1988-1960): articulações entre antropologia, nacionalismo e colonialismo em Portugal”, em A.C. Martins (org.), Mendes Correia (1988-1960): Entre a Ciência, a Docência e a Política. Lisboa, ACD Editores, 9-35.

MUSSOLINI, Gioconda, 1956, "Bibliografia: Jorge Dias, Rio de Onor: Comunitarismo Agro-Pastoril, Revista de Antropologia, 4 (1): 82-86.

OliveirA, Nemuel da Silva, e Marcos Chor MAIO, 2011, "Estudos de comunidade e ciências sociais no Brasil”, Revista Sociedade e Estado, 26 (3): 521-550, disponível em $<$ http://www.scielo.br/scielo.php?script=sci_arttext\&pid =S0102-699220110003000 $06>$ (última consulta em outubro de 2016).

OliveirA, Roberto Cardoso de, 1960, Processo de Assimilação dos Terêna. Rio de Janeiro, Museu Nacional.

PEIRANO, Mariza, 1981, The Anthropology of Anthropology: The Case of Brazil. Harvard, Harvard University, tese de doutorado.

PEIXOTO, Fernanda Arêas, e Julio Assis SIMÕES, 2003, "A Revista de Antropologia e as ciências sociais em São Paulo: notas sobre uma cena e alguns debates”, Revista de Antropologia , 46 (2): 383-409, disponível em <http://www.scielo.br/scielo.php?script=sci_arttext\&pid=S00 34-77012003000200009\&lng=pt\&nrm =iso $>$ (última consulta em outubro de 2016). ROQUE, Ricardo, 2010, Headhunting and Colonialism: Anthropology and the Circulation of Human Skulls in the Portuguese Empire, 1870-1930. Hampshire, Palgrave Macmillan.

SCHADEN, Egon, 1954, Aspectos Fundamentais da Cultura Guarani. São Paulo, Editora Pedagógica Universitária/Editora da Universidade de São Paulo. 
STOCKING Jr., George, 1982, “Afterward: a view from the center”, Ethnos, 47, 172-286.

VIEGAS, Susana de Matos, e João de PINA-CABRAL, 2014, "Na encruzilhada portuguesa: a antropologia contemporânea e a sua história”, Etnográfica, 18 (2): 31 1-332, disponível em < https://etnografica.revues.org/3694 > (última consulta em outubro de 2016).

VILHENA, Luís Rodolfo, 1997, Projeto e Missão: O Movimento Folclorista Brasileiro (1947-64).

Rio de Janeiro, Funarte/Fundação Getulio Vargas.

WILLEMS, Emílio, 1955, "A família portuguesa contemporânea”, Sociologia, 17 (1): 3-55. 